\title{
Adenovirus-mediated bone morphogenetic protein-2 promotes osteogenic differentiation in human mesenchymal stem cells in vitro
}

\author{
HONG CAO $^{1 *}$, ZHI-BO SUN $^{1 *}$, LEI ZHANG $^{1}$, WEI QIAN ${ }^{1}$, CHUN-YANG LI $^{2}$, \\ XIAO-PENG GUO ${ }^{3}$ and YING ZHANG ${ }^{2}$ \\ Departments of ${ }^{1}$ Orthopedic Surgery and ${ }^{2}$ Reproductive Medicine, Renmin Hospital; \\ ${ }^{3}$ Department of Orthopedic Surgery, Taihe Hospital, Hubei University of Medicine, Shiyan, Hubei 442000, P.R. China
}

Received July 25, 2015; Accepted March 17, 2017

DOI: $10.3892 /$ etm.2017.4482

\begin{abstract}
Delayed and failed bone union following fracture is a common clinical complication that requires treatment in orthopedics. Cell-based therapies and tissue-engineering approaches are potential therapeutic strategies for bone repair and fracture healing. However, the effect of adenovirus expressing bone morphogenetic protein-2 (Ad-BMP-2) on the osteogenic ability of human mesenchymal stem cells (hMSCs) has remained to be fully elucidated. Therefore, in the present study, hMSCs were transduced using Ad-BMP-2 to assess the effects of its application and to determine whether Ad-BMP-2 promotes the osteogenic differentiation of hMSCs. The purity of the hMSC cultures was assessed using flow cytometric analysis. In order to assess the osteogenic activity, alkaline phosphatase activity (ALP) was measured and to estimate the osteoblastic mineralization and calcification, von Kossa staining for phosphates was performed. Cells positive for Src homology 2 domain were determined to be hMSCs and the presence of CD34 was used to distinguish hematopoietic lineages. Following treatment, the Ad-BMP-2 and control group had significantly increased ALP levels $(\mathrm{P}<0.05)$. Compared to the blank group and the group transfected with adenoviral vector containing LacZ, the phosphate deposition in the Ad-BMP-2 group and the positive control group treated with dexamethasone was markedly increased. The results of the present study suggested that Ad-BMP-2 promotes osteogenic differentiation in hMSCs and may have a potential
\end{abstract}

Correspondence to: Ms. Ying Zhang, Department of Reproductive Medicine, Renmin Hospital, Hubei University of Medicine, 39 Chaoyang Middle Road, Shiyan, Hubei 442000, P.R. China E-mail: 33556511@qq.com

${ }^{*}$ Contributed equally

Key words: adenovirus, bone morphogenetic protein-2, osteogenic differentiation, human mesenchymal stem cells application in treating delayed union and nonunion following bone fracture.

\section{Introduction}

Delayed or failed bone union is a common clinical complication that requires treatment in orthopedics, often requiring re-admission and surgery (1). Depending on the fracture site, $\sim 5-10 \%$ of fractures may result in delayed union or nonunion (2,3). Previously, autogenous bone grafts or free vascularized bone grafts have been widely used for nonunion treatment. However, harvesting the grafts from the iliac crest is associated with donor site morbidity and particularly with chronic pain (4).

Cell-based therapies and tissue-engineered approaches have become potential therapeutic strategies for bone repair and fracture healing. Producing an optimal cell source for the generation of functional osteoblasts is critical to achieve clinical success with these therapeutic strategies. Mesenchymal stem cells (MSCs) are multipotent somatic stem cells that are able to differentiate into numerous of cell types, including chondrocytes, myocytes, osteoblasts and adipocytes (5). It has been demonstrated that MSCs may provide a source of cells for tissue engineering of bone tissue. The osteogenic potential of MSCs has already been applied in a number of clinical situations, including fracture nonunion, osteogenesis imperfecta, posterior spinal fusion, distraction osteogenesis and osteoarthritis (6). The number of human (h)MSCs in tissue and their proliferative activity has been observed to be reduced with increasing age of their donor (7), which leads to difficulties in preparing a sufficient number of hMSCs for cell therapy in elderly patients. In addition, hMSCs isolated from patients with osteoporosis exhibit a low proliferative activity and limited ability to differentiate into the osteogenic lineage $(8,9)$.

It has been demonstrated that bone morphogenetic proteins (BMPs) have crucial roles in the process of new bone formation by inducing the differentiation of hMSCs into osteoblasts, and promoting osteoblast maturity and endochondral ossification (10). Among the BMPs studied (BMP-2, -7 and -9), BMP-2 has the highest osteoinductive potential (11). Due to the 
efficient gene transfer achieved, adenoviral vectors are attractive vehicles for in vivo gene therapy. It has been demonstrated that BMP-2-expressing recombinant adenoviral vector gene (Ad-BMP-2)-modified tissue-engineered bone may efficiently promote osteogenesis and repair critical-sized bone defects in large animals (12). However, the effect of Ad-BMP-2 on the osteogenic ability of human mesenchymal stem cells has remained elusive.

Therefore, the present study assessed the possible application of Ad-BMP-2 in order to assess whether it promotes osteogenic differentiation of hMSCs. In the present study, the feasibility of using hMSCs in the treatment of delayed and nonunion complications of fracture repair in vitro was verified to potentially identify a novel method for treating delayed or failed bone union.

\section{Materials and methods}

hMSC isolation and culture. hMSCs were prepared as described previously (13) following the standard protocol by Roseti et al (14). Bone marrow aspirates $(50 \mathrm{ml})$ were obtained from the iliac crest of 8 healthy volunteer donors (20-35 years of age) at Renmin Hospital, Hubei University of Medicine (Shiyan, China), and diluted to 1:3 with Iscove's modified Dulbecco's medium (IMDM; Gibco; Thermo Fisher Scientific Inc., Waltham, MA, USA). Following density gradient centrifugation (750 x g for $20 \mathrm{~min})$, the mononuclear cell layer was obtained from the interface. The cells were washed twice with Hanks' balanced saline solution (Beyotime Institute of Biotechnology, Haimen, China), suspended in IMDM, supplemented with $10 \%$ heat-inactivated fetal bovine serum (FBS; Gibco; Thermo Fisher Scientific, Inc.), L-glutamine and Hepes (25 mM), gentamicin $(50 \mu \mathrm{g} / \mathrm{ml})$ and $2 \%$ Ultroser $^{\mathrm{TM}} \mathrm{G}$ Serum Substitute (Pall Corp., Port Washington, NY, USA), plated in $75-\mathrm{cm}^{2}$ flasks at a density of $1.6 \times 10^{5}$ cells $/ \mathrm{cm}^{2}$ and incubated in a humidified atmosphere containing $95 \%$ air and $5 \% \mathrm{CO}_{2}$ at $37^{\circ} \mathrm{C}$. After 2 days, when the cells had reached confluence, adherent cells were harvested by incubation for $10 \mathrm{~min}$ with $0.02 \%$ EDTA and $0.05 \%$ trypsin at room temperature. Hanks' balanced saline solution, without calcium and magnesium, supplemented with $10 \%$ FBS was used to wash the cells. Cells were resuspended in the aforementioned complete IMDM. The resulting cell population was referred to as primary culture (P0). Cells were plated at a density of $10^{4}$ cells $/ \mathrm{cm}^{2}$ in $100-\mathrm{mm}$ dishes to propagate this population (secondary culture; P1). The use of human bone marrow for this study was approved by the Human Research Ethics Board at Hubei University of Medicine. All patients provided informed consent.

hMSC characterization and phenotype. Following 14 days, the P0 cultures were trypsinized and passaged. Cell cultures were passaged weekly following P1 and grew exponentially. To assess the purity of the hMSC cultures, analysis of these cells was performed using a flow cytometer (CytoFLEX; Beckman Coulter Inc., Brea, CA, USA). Cells positive for the Src homology 2 domain (SH2) according to flow cytometric analysis with $\mathrm{SH} 2$-fluorescein isothiocyanate-conjugated antibody (cat. no. TA504381; Origene Technologies, Inc., Rockville, MD, USA) were determined to be hMSCs (15).
No detectable contamination with hematopoietic cells was observed, as indicated by the absence of CD34, a marker of the hematopoietic lineage (16), as detected through the use of CD34-FITC-conjugated antibody (cat. no. ZM-0046; Zhongshan Goldenbridge Biotechnology, Ltd., Beijing, China). These data indicated that the population of hMSCs was morphologically homogeneous.

Treatment of cell cultures. Cells at $\mathrm{P} 1$ were randomly divided into four groups, as follows: i) Ad-BMP-2: The concentration of Ad-BMP-2 used in the culture was $1 \times 10^{10}$ optical units/ml, following $24 \mathrm{~h}$ of incubation with Ad-BMP-2 at room temperature, followed by culture in regular culture medium. ii) Adenoviral vector containing LacZ (Ad-LacZ): $1 \times 10^{10}$ optical units/ml Ad-LacZ replaced Ad-BMP-2. iii) Control: The positive control group was cultured with $1 \mathrm{nmol} / \mathrm{l}$ dexamethasone, $50 \mathrm{mg} / \mathrm{l}$ ascorbic acid and $10 \mathrm{mmol} / \mathrm{l}$ $\beta$-sodium phosphate (all from Sigma-Aldrich; Merck KGaA, Darmstadt, Germany) with the medium changed every 3 days. iv) Blank, no specific treatment. The Ad-BMP-2 and Ad-LacZ vectors were constructed and donated by $\mathrm{Li}$ et al (17) at the Department of Trauma Orthopedics, Hubei University of Medicine.

Alkaline phosphatase (ALP) activity assay. To assess osteogenic activity, ALP activity was measured and scored 12 days following transduction. A $100-\mu 1$ sample of the culture supernatant was incubated at $37^{\circ} \mathrm{C}$ for 30 min with $100 \mu \mathrm{l}$ p-nitrophenyl phosphate $(1 \mathrm{mg} / \mathrm{ml}$; Sigma-Aldrich; Merck $\mathrm{KGaA}$ ) in $1 \mathrm{M}$ diethanolamine buffer containing $0.5 \mathrm{mM}$ $\mathrm{MgCl}_{2}$ at $\mathrm{pH}$ 9.8. The addition of $50 \mu 10.2 \mathrm{M}$ sodium hydroxide stopped the reaction. Total protein content was determined using a Bio-Rad Protein Assay kit II (Bio-Rad Laboratories, Inc., Hercules, CA, USA), the absorbance was determined at $595 \mathrm{~nm}$ and the activity was calculated according to a series of bovine serum albumin standards. At the end of the experiment, ALP levels were normalized to the total protein content. Each sample was repeated in triplicate.

von Kossa staining. Cells were fixed with $4 \%$ paraformaldehyde and washed in phosphate-buffered saline. Cells were then treated with $5 \%$ silver nitrate solution at $37^{\circ} \mathrm{C}$ in the dark for $30 \mathrm{~min}$. Silver nitrate solution was then completely washed away with Hanks' balanced saline solution and the cells were exposed to bright light for $15 \mathrm{~min}$ to develop the color.

Statistical analysis. Values are expressed as the mean \pm standard deviation. Statistical analysis was performed using SPSS software, version 12.0 (SPSS, Inc., Chicago, IL, USA). One-way analysis of variance was used to assess the differences between the three groups. $\mathrm{P}<0.05$ was considered to indicate a statistically significant difference.

\section{Results}

Characterization and phenotype of hMSCs. Following four days in culture, freshly harvested bone marrow cells were adherent (Fig. 1A). On day 14, a morphologically homogeneous population of fibroblast-like cells was observed to have $>90 \%$ confluence (Fig. 1B). 

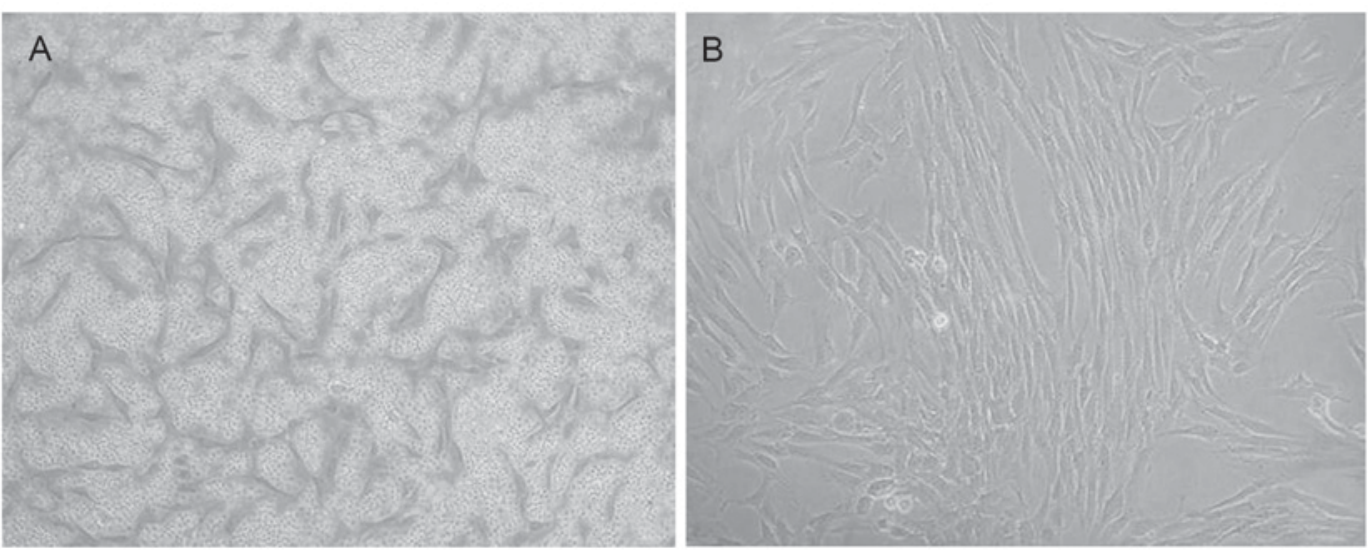

Figure 1. Morphological features of human mesenchymal stem cells imaged using inverted phase contrast microscopy (magnification, x100). Images were captured following (A) 4 days in culture, showing that freshly harvested bone marrow cells were adherent and (B) 14 days, showing a morphologically homogeneous population of fibroblast-like cells.

A

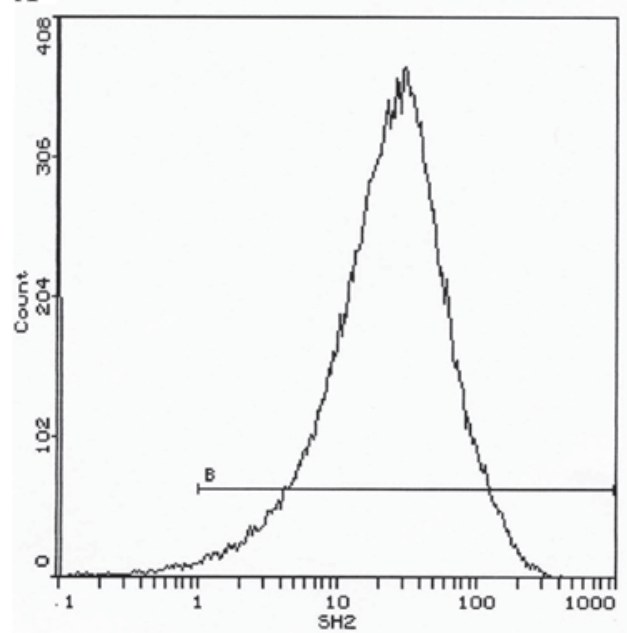

B

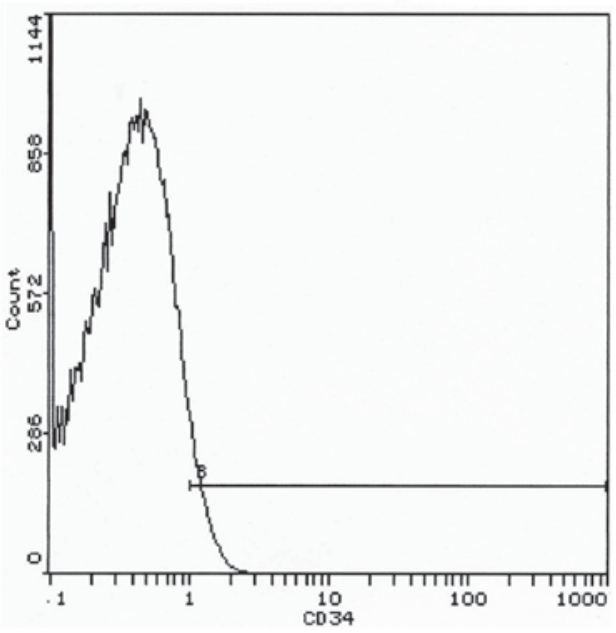

Figure 2. Flow cytometry was used to analyze the phenotype of human mesenchymal stem cells. (A) Cells positive for SH2 were determined. (B) Cells negative for CD34 were assessed to distinguish them from hematopoietic lineages. SH2, Src homology 2 domain.

The phenotype of hMSCs was analyzed using flow cytometry, and cells positive for SH2 were determined to be hMSCs (Fig. 2A), while CD34 was assessed to distinguish the cells from hematopoietic lineages (Fig. 2B).

Ad-BMP-2 induces osteoblast-like morphological changes in hMSCs. Following treatment with Ad-BMP-2, cells gradually transformed into polygons or irregular shapes, proliferation decreased and no colony formation was observed (Fig. 3A). The morphology in the positive control group was similar to that of the hMSCs treated with Ad-BMP-2. There was no evident change in the morphology of hMSCs in the Ad-LacZ group (Fig. 3B) and cells in the blank group, and colony formation was observed.

Ad-BMP-2 increases ALP activity in hMSCs. ALP is an enzyme present in osteoblasts and is pivotal for bone mineralization (18). The present study evaluated the osteoinductive effect of BMP-2 on hMSCs. Following treatment, the Ad-BMP-2 and positive control group demonstrated a significant increase in the level of ALP ( $<<0.05$; Fig. 4).
Ad-BMP-2 increases mineralization and calcification of hMSCs. The mineralization and calcification of the bone matrix facilitates osteoblast formation and is therefore essential for the strength and rigidity of the skeletal system (19). To estimate the osteoblastic mineralization and calcification, von Kossa staining for phosphates at was performed day 14 . Representative images of von Kossa stain were obtained by microscopy (Fig. 5). Compared with the Ad-LacZ and blank groups, the phosphate deposition in the Ad-BMP-2 and positive control groups was clearly increased (Fig. 5).

\section{Discussion}

The US Food and Drug Administration (FDA) define a nonunion as a fracture that does not heal within nine months and reports nonunion occurring in 1 out of 40 fractures (20). A lack of healing progression within three consecutive months is the clinical definition of a delayed union (21). Certain risk factors may predispose a patient to the development of a nonunion, including the type and site of fracture, fracture comminution with bone and soft tissue devascularization, 

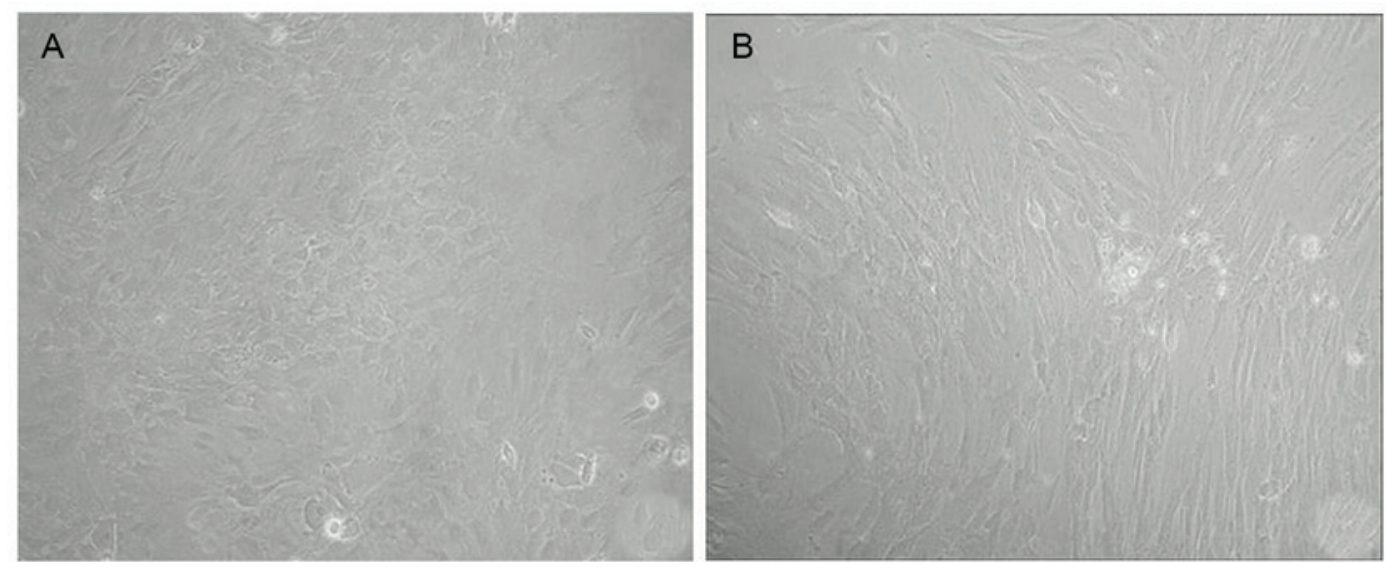

Figure 3. Morphological features of human mesenchymal stem cells treated with Ad-BMP-2 and Ad-LacZ (magnification, x100). (A) Following $24 \mathrm{~h}$ of incubation with Ad-BMP-2, cells gradually transformed into polygons or irregular shapes, the proliferation rate decreased and there was no clear colony formation. (B) Following $24 \mathrm{~h}$ of incubation with Ad-LacZ, cells were spindle-shaped and formed colonies. Ad-BMP-2, adenovirus expressing bone morphogenetic protein-2; Ad-LacZ, adenoviral vector containing LacZ.

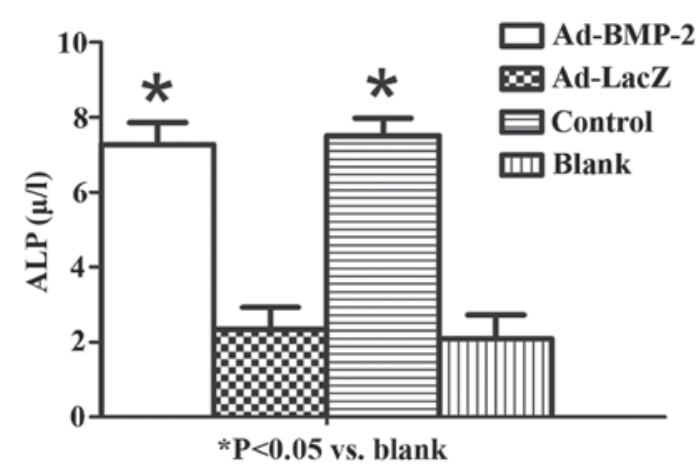

Figure 4. Expression of ALP activity was measured and scored 12 days after transduction to assess osteogenic activity. Following treatment of the four groups, a significant increase in the ALP activity was observed in the Ad-BMP-2 and control groups. "P $<0.05$ vs. blank. Ad-BMP-2, adenovirus expressing bone morphogenetic protein-2; Ad-LacZ, adenoviral vector containing LacZ; blank, no specific treatment; ALP, alkaline phosphatase.

instability, bone loss, presence of a chronic illness, infection and tobacco use. However, while it is known that these risk factors may predispose a patient to develop a nonunion, the underlying physiopathology remains to be fully elucidated (22).

Human marrow mesenchymal stem cells have become the primary cell source for bone tissue engineering (23). The theory of osteoblast modulation suggests that if a pluripotent cell is situated in the proper milieu it may convey an osteoblast phenotype (24). As described by Chamberlain et al (25), a several week incubation procedure that includes a mixed monolayer of hMSCs with ascorbic acid, dexamethasone and phosphate is the standard approach for differentiating hMSCs into osteoblasts in vitro (25), so the present study used this as a positive control. The methods typically used to incubate hMSCs include whole bone marrow culture, density gradient centrifugation and immunomagnetic separation. The primary hMSCs separated by the final two methods have relatively high purity, but the cells grow slowly and the culture cycle is long, making it difficult to meet clinical requirements $(26,27)$. The primary cells incubated using the whole marrow method are mixed with hemopoietic stem cells. However, with Ad-BMP-2 and the extension of the incubation time, the suspension growth

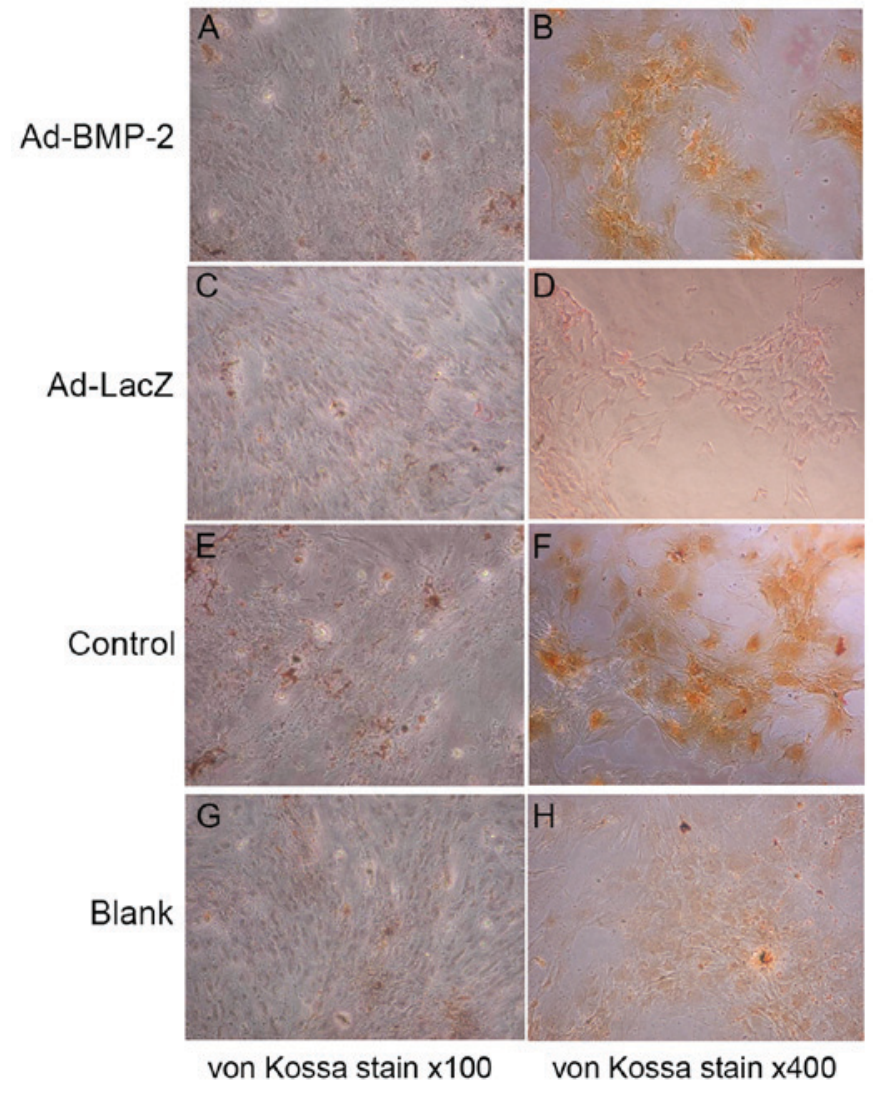

Figure 5. Estimation of the osteoblastic mineralization and calcification was performed using a von Kossa stain for phosphates at day 14. Representative images of von Kossa-stained cells were obtained via microscopy for each group. (A and B) Ad-BMP-2, (C and D) Ad-LacZ, (E and F) control and $(\mathrm{G}$ and $\mathrm{H}$ ) blank (magnification, $\mathrm{x} 100$ in the left and $\mathrm{x} 400$ in the right panel). Compared to the Ad-LacZ and blank groups, the phosphate deposition in the Ad-BMP-2 and control groups was clearly increased. Ad-BMP-2, adenovirus expressing bone morphogenetic protein-2; Ad-LacZ, adenoviral vector containing LacZ; blank, no specific treatment.

hemopoietic stem cells are removed through the exchange of cell medium. The present study assessed the use of Ad-BMP-2 with an extended incubation time using flow cytometry, confirming that the whole bone marrow culture also reach a 
high purity, the cells multiply rapidly and the culture cycle is short, meaning it is suitable for clinical use.

To improve the osteogenic potential, two strategies have been developed. The first one is to enhance bone formation by incorporating bone-favor growth factors into the scaffold, known as growth factor-based bone tissue engineering. The second is cell-based bone tissue engineering, building up osteoinductive capability by growing living osteogenic cells on scaffolds in vitro (28). Numerous members of the whole BMP superfamily are associated with bone, cartilage and joint development. BMP-2 has been approved by the FDA for clinical practice as the most potent member of the BMP family in promoting bone and cartilage development. It is therefore a popular choice for MSCs-based bone tissue engineering. It has been demonstrated that the BMP-2-modified MSCs increase the ALP activity, cell proliferation and mineralization in vitro and heal critical-size bone defects, induce ectopic bone formation, repair fractures and trigger spinal fusion in vivo (29). BMP-2 serves an important role in fracture healing: During the process of bone tissue repair, BMP-2 transmits information between cells and intercellular substances through autocrine and paracrine signaling, regulating the secretion and proliferation of cells. The adenovirus commonly used as a gene delivery vector as it has a high transfection efficiency (30). However, the long-term overexpression of exogenous genes may lead to serious consequences, which are unpredictable and irreparable. However, the target genes that the adenovirus is able to mediate do not integrate into the chromosome, are only expressed in the cytoplasm and typically last for 4-8 weeks (31). Therefore, the requirement of gene therapy to be delivered quickly is satisfied while safety is guaranteed.

The flexibility to express the protein focally and locally, or in a disseminated fashion, as required is the most relevant advantage of gene therapy. Of note, gene therapy provides a possibility for intra-cellular production of proteins, thus facilitating therapeutic pathways to occur (32). Following treatment with Ad-BMP-2, hMSCs not only adopted osteoblastic features regarding their shape and growth patterns, but also had an increased expression of ALP. The present study also used a group transfected with Ad-LacZ to assess whether the expression of the adenoviral vector, which was identical to that in Ad-BMP-2, had any effect on osteogenesis. The results suggested that the stimulation of osteogenesis in the Ad-BMP-2 group was a result of the expression of BMP-2, not the adenovirus.

If active bone formation occurs, the level of ALP increases, as it is a byproduct of osteoblast activity (33). In the present study, the culture medium was changed to be serum-free prior to ALP detection. This eliminates any interference with the results due to ALP contained in serum. Osteoblastic mineralization and calcification are the most reliable evidence of the osteoblast. In the Ad-BMP-2 and positive control groups, ALP activity and the level of phosphate increased, indicating that Ad-BMP-2 has a function in promoting the osteogenesis of hMSC.

The present study confirmed the feasibility of transfecting hMSCs with Ad-BMP-2 to treat delayed or nonunion fractures in vitro. In addition, hMSCs may differentiate into chondrocytes, myocytes and adipocytes as well as osteoblasts. Therefore, it is necessary to induce osteoblastic differentiation prior to transplantation. The traditional method to induce osteoblast proliferation is to administer dexamethasone, ascorbic acid and $\beta$-sodium phosphate. The present study demonstrated that the osteogenic differentiation ability of hMSCs in the Ad-BMP-2 group was similar to that in the positive control group. The induction time was two weeks in the positive control group, while it was only $24 \mathrm{~h}$ in the Ad-BMP-2 group, suggesting that Ad-BMP-2 may reduce osteogenic differentiation time. As for clinical use, Ad-BMP-2 may significantly reduce the treatment cycle time and the risk of cell contamination with hematopoietic cells. Therefore, it has the potential to be a novel therapeutic method for treating delayed or nonunion fracture healing in the future.

\section{Acknowledgements}

The present study was supported by the National Natural Science Foundation of China (grant no. 81602867), Hubei Province Health and Family Planning Scientific Research Project (no. WJ2015Q042) and projects funded by Hubei Provincial Science and Technology Department (no. 2013CFC031).

\section{References}

1. Dahabreh Z, Dimitriou R and Giannoudis PV: Health economics: A cost analysis of treatment of persistent fracture non-unions using bone morphogenetic protein-7. Injury 38: 371-377, 2007.

2. Marsh D: Concepts of fracture union, delayed union, and nonunion. Clin Orthop Relat Res (Suppl 355): 22-30, 1998.

3. Obermeyer TS, Yonick D, Lauing K, Stock SR, Nauer R, Strotman P, Shankar R, Gamelli R, Stover M and Callaci JJ: Mesenchymal stem cells facilitate fracture repair in an alcohol-induced impaired healing model. J Orthop Trauma 26: 712-718, 2012.

4. Qi Y, Zhao T, Yan W, Xu K, Shi Z and Wang J: Mesenchymal stem cell sheet transplantation combined with locally released simvastatin enhances bone formation in a rat tibia osteotomy model. Cytotherapy 15: 44-56, 2013.

5. Aldahmash A, Zaher W, Al-Nbaheen M and Kassem M: Human stromal (mesenchymal) stem cells: Basic biology and current clinical use for tissue regeneration. Ann Saudi Med 32: 68-77, 2012.

6. Zhang ZY, Teoh SH, Hui JH, Fisk NM, Choolani M and Chan JK: The potential of human fetal mesenchymal stem cells for off-the-shelf bone tissue engineering application. Biomaterials 33: 2656-2672, 2012.

7. D'Ippolito G, Schiller PC, Ricordi C, Roos BA and Howard GA: Age-related osteogenic potential of mesenchymal stromal stem cells from human vertebral bone marrow. J Bone Miner Res 14: 1115-1122, 1999.

8. Rodríguez JP, Ríos S, Fernández $M$ and Santibañez JF: Differential activation of ERK1,2 MAP kinase signaling pathway in mesenchymal stem cell from control and osteoporotic postmenopausal women. J Cell Biochem 92: 745-754, 2004.

9. Rodríguez JP, Montecinos L, Ríos S, Reyes P and Martínez J: Mesenchymal stem cells from osteoporotic patients produce a type I collagen-deficient extracellular matrix favoring adipogenic differentiation. J Cell Biochem 79: 557-565, 2000.

10. Finkemeier CG: Bone-grafting and bone-graft substitutes. J Bone Joint Surg Am 84-A: 454-464, 2002.

11. Cheng H, Jiang W, Phillips FM, Haydon RC, Peng Y, Zhou L, Luu HH, An N, Breyer B, Vanichakarn P, et al: Osteogenic activity of the fourteen types of human bone morphogenetic proteins (BMPs). J Bone Joint Surg Am 85-A: 1544-1552, 2003.

12. Dai KR, Xu XL, Tang TT, Zhu ZA, Yu CF, Lou JR and Zhang XL: Repairing of goat tibial bone defects with BMP-2 gene-modified tissue-engineered bone. Calcif Tissue Int 77: 55-61, 2005.

13. Sun D, Junger WG, Yuan C, Zhang W, Bao Y, Qin D, Wang C, Tan L, Qi B, Zhu D, et al: Shockwaves induce osteogenic differentiation of human mesenchymal stem cells through ATP release and activation of $\mathrm{P} 2 \mathrm{X} 7$ receptors. Stem Cells 31: 1170-1180, 2013. 
14. Roseti L, Serra M and Bassi A: Standard operating procedure for the good manufacturing practice-compliant production of human bone marrow mesenchymal stem cells. Methods Mol Biol 1283: 171-186, 2015.

15. Foster LJ, Zeemann PA, Li C, Mann M, Jensen ON and Kassem M: Differential expression profiling of membrane proteins by quantitative proteomics in a human mesenchymal stem cell line undergoing osteoblast differentiation. Stem Cells 23: 1367-1377, 2005.

16. Hammoud M, Vlaski M, Duchez P, Chevaleyre J, Lafarge X, Boiron JM, Praloran V, Brunet De La Grange P and Ivanovic Z: Combination of low $\mathrm{O}(2)$ concentration and mesenchymal stromal cells during culture of cord blood CD34(+) cells improves the maintenance and proliferative capacity of hematopoietic stem cells. J Cell Physiol 227: 2750-2758, 2012.

17. Li WC, Wang DP, Li LJ, Zhu WM and Zeng YJ: Adenovirusmediated bone morphogenetic protein-2 gene transfection of bone marrow mesenchymal stem cells combined with nano-hydroxyapatite to construct bone graft material in vitro. Artif Cells Nanomed Biotechnol 41: 103-108, 2013.

18. Mukaiyama K, Kamimura M, Uchiyama S, Ikegami S, Nakamura Y and Kato H: Elevation of serum alkaline phosphatase (ALP) level in postmenopausal women is caused by high bone turnover. Aging Clin Exp Res 27: 413-418, 2013.

19. Williams DC and Frolik CA: Physiological and pharmacological regulation of biological calcification. Int Rev Cytol 126: 195-292, 1991.

20. Zura R, Braid-Forbes MJ, Jeray K, Mehta S, Einhorn TA, Watson JT, Della Rocca GJ, Forbes K and Steen RG: Bone fracture nonunion rate decreases with increasing age: A prospective inception cohort study. Bone 95: 26-32, 2017.

21. Liebergall M, Schroeder J, Mosheiff R, Gazit Z, Yoram Z, Rasooly L, Daskal A, Khoury A, Weil Y and Beyth S: Stem cell-based therapy for prevention of delayed fracture union: A randomized and prospective preliminary study. Mol Ther 21: 1631-1638, 2013.

22. Mathieu M, Rigutto S, Ingels A, Spruyt D, Stricwant N, Kharroubi I, Albarani V, Jayankura M, Rasschaert J, Bastianelli E and Gangji V: Decreased pool of mesenchymal stem cells is associated with altered chemokines serum levels in atrophic nonunion fractures. Bone 53: 391-398, 2013.
23. Jiang X, Zou S, Ye B, Zhu S, Liu Y and Hu J: bFGF-Modified BMMSCs enhance bone regeneration following distraction osteogenesis in rabbits. Bone 46: 1156-1161, 2010.

24. Cuomo AV, Virk M, Petrigliano F, Morgan EF and Lieberman JR: Mesenchymal stem cell concentration and bone repair: Potential pitfalls from bench to bedside. J Bone Joint Surg Am 91: 1073-1083, 2009.

25. Chamberlain G, Fox J, Ashton B and Middleton J: Concise review: Mesenchymal stem cells: Their phenotype, differentiation capacity, immunological features, and potential for homing. Stem Cells 25: 2739-2749, 2007.

26. Quent VM, Theodoropoulos C, Hutmacher DW and Reichert JC: Differential osteogenicity of multiple donor-derived human mesenchymal stem cells and osteoblasts in monolayer, scaffold-based 3D culture and in vivo. Biomed Tech (Berl) 61: 253-166, 2016.

27. Lee TH, Kim WT, Ryu CJ and Jang YJ: Optimization of treatment with recombinant FGF-2 for proliferation and differentiation of human dental stem cells, mesenchymal stem cells, and osteoblasts. Biochem Cell Biol 93: 298-305, 2015.

28. Meijer GJ, de Bruijn JD, Koole R and van Blitterswijk CA: Cell-based bone tissue engineering. PLoS Med 4: e9, 2007.

29. Hong D, Chen HX, Ge R and Li JC: Genetically engineered mesenchymal stem cells: The ongoing research for bone tissue engineering. Anat Rec (Hoboken) 293: 531-537, 2010.

30. Rastall DP and Amalfitano A: Recent advances in gene therapy for lysosomal storage disorders. Appl Clin Genet 8: 157-169, 2015.

31. Liddle OL, Samuel MI, Sudhanva M, Ellis J and Taylor C: Adenovirus urethritis and concurrent conjunctivitis: A case series and review of the literature. Sex Transm Infect 91: 87-90, 2015.

32. Balmayor ER and van Griensven M: Gene therapy for bone engineering. Front Bioeng Biotechnol 3: 9, 2015.

33. Pruessner HT: Detecting celiac disease in your patients. Am Fam Physician 57: 1023-1034, 1039-1041, 1998. 